\title{
An investigation on sustainability indicators of vernacular environments: the case of Cyprus
}

\author{
M. Oktay \& O. Dincyurek \\ Department of Architecture, Eastern Mediterranean University, \\ North Cyprus
}

\begin{abstract}
In general, vernacular environments might be described as the settings which occurred as the products of the socio-cultural, economic and especially local characteristics of the particular region by and for the inhabitants of that region. When these environments are considered, it is obvious that the main considerations of the builders and/or the owners of them were to achieve functionally proper and environmentally appropriate solutions for themselves. In this respect, the way of life, climate, topography, available material and existing building technology might be described as the formative concerns of vernacular environments in general and in Cyprus as well.

On the other hand, when housing developments today on the Island of Cyprus and their problems are investigated, it might be easily perceived that most of them fail to fit to the existing environmental conditions because of the lack of consideration given to the ecosystem.

As time changes, the needs, requirements and especially the way of life change. Therefore the need to transform and adapt houses, villages, cities etc to the changing and developing conditions is inevitable. However, while performing these changes it is important to investigate the vernacular houses and their settings, which were developed harmoniously with the ecosystem of a particular region and act as sustainability indicators.

In brief, this study aims to investigate the particular vernacular houses and settings of Cyprus, to find out the main characteristics of them in the manner of responding to the environmental and cultural values. We intend to list these characteristics in order to provide a vision for future housing developments to achieve environmentally sustainable developments in Cyprus.
\end{abstract}

Keywords: vernacular, environmental values, sustainability, Cyprus. 


\section{Introduction}

Cyprus is the third largest island in the Mediterranean Sea. Because of its strategic importance by being located on the crossroads of trade and culture it had been ruled by various civilizations. Hill describes [1] Phoenicians, Assyrians, Egyptians, Persians, Hellenics, Romans, Byzantines, Arabs, Franks, Genoveses, Venetians, Ottomans and British as the rulers of the island throughout its history. Accordingly, it is possible to observe a variety in the built environment of the island, which occurs as a result of these settlers.

But, there is no need to be an architect to observe the decay and demolishment in the natural and built environment of North Cyprus. Starting from a long time ago, but especially in last decade, the building development in the island has unfortunately destroyed the flora, parallel to this fauna, natural resources and cultural heritages; vernacular environments of the island. The main reasons for these unconsciously realized enterprises might be described as the 'comfort', 'modern' and luxury exploration of the people, either islanders or foreigners, as clients of these newly constructed areas.

Predominantly, clients do not consider the environmental features of the island while they are looking for a new house. Their main demand is to own a 'new, comfortable, modern looking, luxurious house'. Additionally the construction firms, the number of which cannot be easily counted these days, do not respect the culture and nature of the island while proposing new housing alternatives. Even in some cases imported house prototypes are applied. In short, there is no cultural and environmental respect in the new developments.

On the other hand, vernacular environments on the island look like the built clues of how a house can be integrated with the nature, culture and environmental values. There is much to learn from them in this manner. For these reasons, the aim of this study is to investigate vernacular environments and find out their characteristics in order to provide a vision for the future housing developments to achieve environmentally sustainable developments.

In this manner, cultural attributes and environmental factors might be described as the two key subjects while studying vernacular contexts in general and in Cyprus as well. Although strong cultural impacts exist on the formation process of the vernacular settings, only the environmental influences are discussed in this study in order to put forward the relation between these environments and the ecosystem of the related setting.

Another reason to focus on the environmental issues is the prevalently discussed topics of today: global warming. The climate, topography and building materials used can be listed as the static features of the particular area. Although the topography and available material is same, there are changes in the weather. In this line, saving the resources became the most important duty of human beings. Therefore, instead of neglecting the environmental parameters through the design process and spending recourses for heating/cooling, lighting etc. it is important to consider them and provide an environmentally appropriate solution.

On the other hand, when daily routine, economy, social intercourse and these kinds of cultural attributes are considered it is seen that they show 
differentiations and variations due to the change in time. Since these changes will continue through time, it might not be possible or suitable to suggest proper solutions for the future.

\section{Vernacular environments of Cyprus}

In the Encyclopaedia of Vernacular Architecture of the World, Oliver [2] argues that it may be ill-advised to look for a single definition of vernacular architecture because of its variety. Nevertheless he defines this term as: vernacular architecture includes the dwellings and all other buildings of the people which are usually built by the owner or community in relation with their environmental contexts by using existing resources with traditional technologies. Besides, he adds that the forms of this architecture are built to meet particular needs. They include the values, economies and ways of living of their cultures.

Moreover, Brunskill [3] defines the term vernacular architecture as that sort of building which is deliberately permanent rather than temporary, which is traditional rather than academic in its inspiration, which provides for the simple activities of ordinary people, their farms and their simple industrial enterprises, which is strongly related to place, especially through the use of local building materials, but which represents design and building with thought and feeling rather than in a base or strictly utilitarian manner.

In general it might be described that, vernacular architecture represents all kinds of buildings that are produced by the native people by utilizing locally available materials with the help of simple tools and existing technology as well as deeply considering the cultural features [4, p. 12].

As can be easily understood from the definitions of 'vernacular architecture' it might be said that every country, city and even region as well has its own specific house type varied according to the changing environmental circumstances and cultural characteristics.

By considering these, the vernacular architecture of the island could be investigated under two fields [5], which can be subjected as rural and urban vernacular. Although geographical, topographical, climatic parameters and the availability of building materials generally denote the similar characteristics, certain differences are clearly observed in the building activity of both fields [6].

Rural vernacular forms were developed according to the response of the agrarian way of life, available local building materials and climatic conditions. In spite of religious, ethnical and regional differences, the agricultural way of life and economy have been the primary determinants of shared rural values and consequent rural vernacular architecture of the island as Dincyurek [7] mentions. On the other hand, Pulhan [8] states that the traditional urban form of the island was mainly influenced by the prevailing cultures and the imported lifestyles, fig. 1 . 

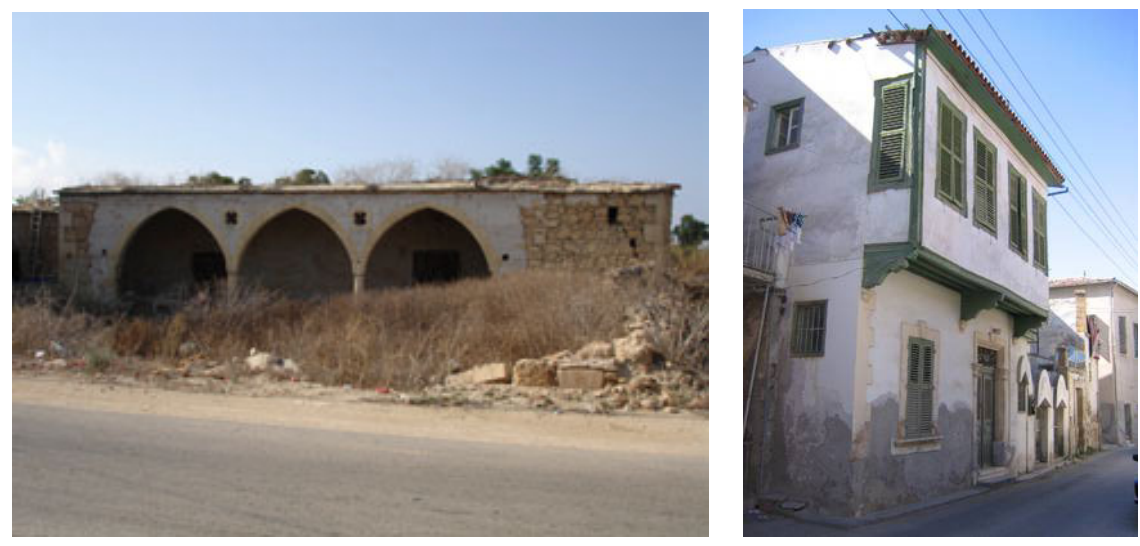

Figure 1: Examples for rural and urban vernacular house, Cyprus.

\section{Sustainability indicators of vernacular environments}

Although the vernacular architecture of the Island can be investigated under two topics as rural and urban, only the rural vernacular architecture is going to be discussed in this study as a correct answer to the local and environmental needs. Therefore, the environmental characteristics and the space use of the rural vernacular architecture of North Cyprus are going to be evaluated in order to find the sustainability indicators.

\subsection{Climatic appropriateness}

Since Cyprus is an island located in the Mediterranean Sea, it has a Mediterranean climate, which can be roughly described as summers are hot, dry and long and winters are warm, rainy and short. Even from this short explanation it can be understood that the most important feature that must have precautions taken for is the heat. Therefore, these precautions can be listed as [4, pp. 49-59]:

- Courtyard wall: Mostly, courtyards were defined by the high stone/adobe walls to provide privacy for the households and also to assure secure spaces from the strong winds, fig. 2.

- Orientation: Orientation of the house is very important aspect for achieving the proper microclimates for spaces. The vernacular houses were mostly oriented by considering the climatic features such as sun and wind factors. Thus, houses were predominantly aligned to the south west-north east direction to provide climatic benefits.

- Semi-open spaces, halls: In some cases, semi-open spaces were developed like an inner hall. These inner halls provide climatically comfortable atmosphere both for hot and cold weathers. They offer cool and shadowy 
area for the severe heat of summer and a warm area for the cold winter. In some cases, arcaded semi-open spaces were developed between closed spaces (inside of the house) and open space (courtyard). As a response to climate, these arcaded façades were mainly facing towards south or south-east direction. They act as a barrier and offer shaded outdoor spaces in the summer whereas they prevent wind flow in the winter. These facades blockade the high and undesirable sun rays of summer and let low desirable rays of the winter sun reach through the semi-open space to the inside of the house, fig.3.

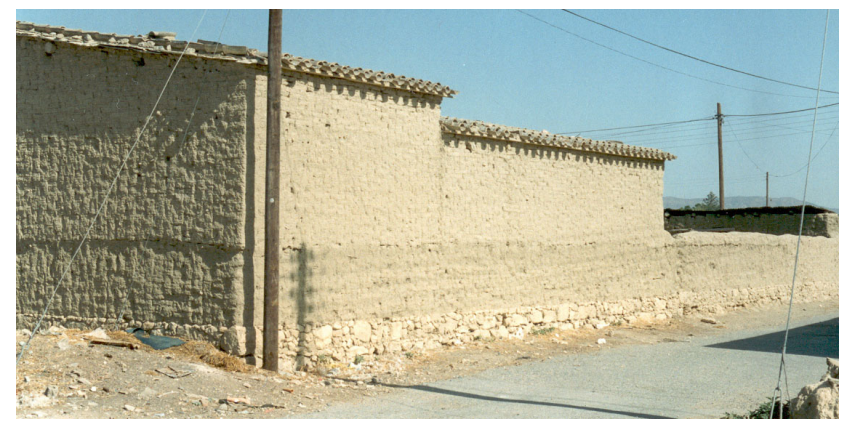

Figure 2: High adobe walls of rural vernacular houses.
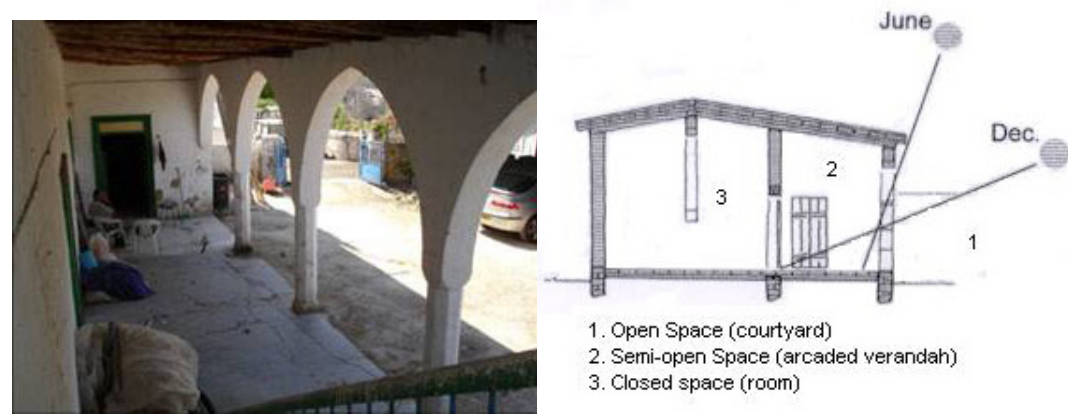

Figure 3: $\quad$ Section of a rural house showing summer and winter sun [9].

- Cross ventilation: There were some attempts to generate cross ventilation. One of them was the addition of the upper ventilation holes on the walls. These holes were mostly small, rectangular or square openings located on higher part of the wall, which are very close to the ceiling. They were generally found on the south-west, north-west and/or north-east façades.

Another attempt was making openings on the top part of the doors. These doors can be both outer and inner doors. Air flows inside the house from these rectangular shape openings and circulates. If the inner doors also have openings, this air enters through the inside to the secondary rooms. Additionally, the warm air flows outside with this circulation path. 
Moreover, ventilation was achieved by the organization of windows and doors. These openings were small and predominantly placed on the southeast and north-west façades (or south and north) of the houses, opposite to each other. Other two façades use to keep close as blind walls. In some of the houses which have second floors, openings on the third and fourth façades were observed in the upper floor. Therefore, these upper stories became much cooler than the lower stories. For this reason, they used were as sleeping space during the hot summer nights, fig. 4.
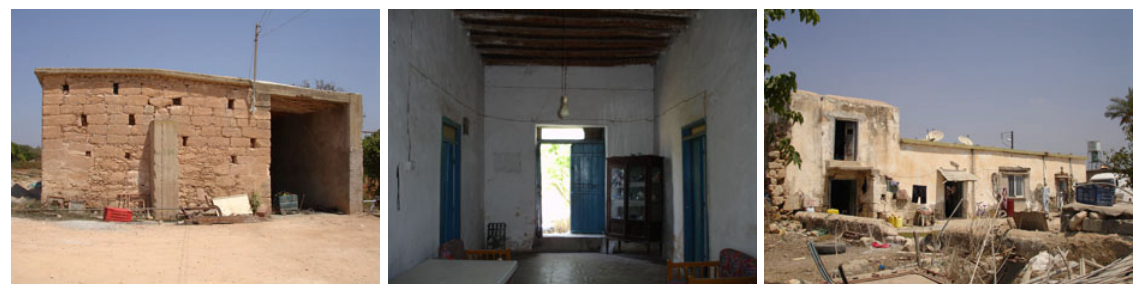

Figure 4: Examples for some attempts to achieve cross ventilation.

- Building material: Stone and adobe are the available building material for wall construction in general. As a response to the climatic features, thick walls were developed. These thick walls provide cool environment in the house during the summer and keep the inside warm in winter.

- Hearth: A hearth was found in almost all of the houses. Sometimes, it is possible to observe more than one hearth in the same house. It was mainly used for both cooking and heating.

- Roof: Generally, the predominant type of precipitation on the island is rain. For this reason, the roofs were developed with a slight slope. Rain water could easily be reached to the ground through this slight slope without touching the wall surface.

\subsection{Topographic appropriateness}

The northern part of the island is divided into four natural regions; coastal strips, coastal highlands, inner highlands and central lowlands. Besides, the settlement patterns of the island are nucleated, clustered and compact [5, pp. 24, 90]. Generally, villages were settled on (see [4, pp. 60-68] and fig. 5):

- Flat topography, either on the upland or on the lowland.

- Sloped topography.

The vernacular houses and settlements on the island are formed according to the topographic features of the sites as well. Thus, the form of the houses and the settlement pattern are determined according to these features. 

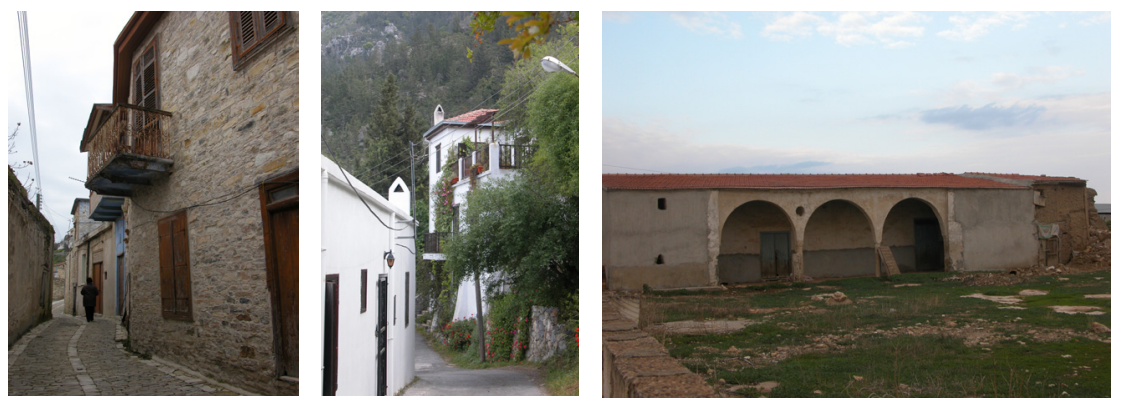

Figure 5: Rural house formation considering different topographies.

\subsection{Appropriateness in building material and construction techniques utilization}

The use of local materials with locally developed construction techniques are common in all vernacular environments. This notion is also mentioned by Aran's [10] definition as: during the selection of indigenous building materials from natural environment, the builder is primarily concerned with whether they can be easily carried to the building site, if they can be worked by means of tools available to him, and if they can be easily joined together. In this line, commonly used materials in the vernacular houses of Cyprus can be listed as [4, pp. 69-77]:

- Earth: When earth is available then the adobe can be developed as a construction technique.

- Stone: When stone is accessible then stone masonry evolved. Cut and rubble stone are the types and various methods of stone masonry can be achieved with the utilization of them.

- Timber: Timber post and beam forms the structural system in some cases. Windows and doors are made of this material. In some cases, where the timber is prevalent, the floor, stairs (in two-story houses) and balustrades are made of timber. Timber rafters are predominantly seen in the formation of the ceiling as well.

- Gypsum: It is used as the finishing material for the roof and in some cases for the walls. Besides, it is used for decoration purposes such as shelves.

- Local marble: In some cases used as floor covering material.

- Reed, Straw and Mat: Used for the roof.

Additionally, load-bearing in the structural system is achieved with stone, earth or both of them.

\subsection{Appropriateness in space and usage}

Dincyurek [5, pp. 11-123] defines the basic components of the rural vernacular houses of the island as living spaces, hall, storage, kitchen, bathroom and toilet, shelter for domestic animals and others, such as well, earth oven, yards. 
The activities in the rural vernacular houses mainly took place in the open air. The rural way of life and appropriate climatic conditions supported the outdoor activities in rural houses, such as cooking, laundering, and leisure [5, p. 111]. For this reason open space, or in other words a courtyard, is very important for the Cypriots. Therefore, instead of grouping spaces like open, semi-open and closed it is preferred to explain them as elements which were located in the open space (courtyard) because of the crucial importance of this space. In this respect the courtyard contains (see [4, pp. 105-121] and fig. 6):

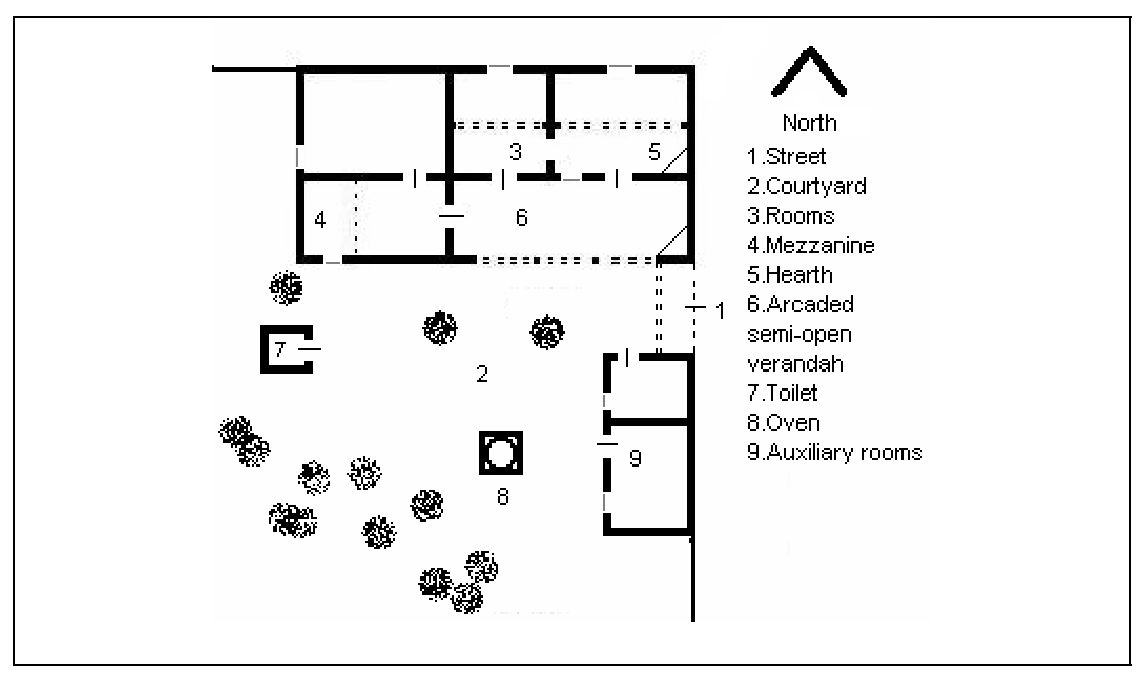

Figure 6: Rural vernacular house plan, [4, p. 106].

- Main house unit: It has two types of spaces: semi-open and closed. Semiopen space is the transitional space between open and closed spaces. It acts as a circulation path between different rooms. This space was widely used during both hot and cold weathers as a result of its climatically responsive identity. Thus, apart from being a circulation path it is used for several activities such as hosting guests, resting, sleeping, laundering, cooking, eating etc. The closed parts of the main house units are the rooms. These rooms are multifunctional spaces. A room can be used as a living room, kitchen, dining room and bedroom.

- Sink, well and oven: Since households use the courtyard for laundering and cooking these elements are essential and widely seen in general.

- Auxiliary rooms: These rooms can mainly be classified as animal shelters and storage for agricultural tools and products. They were located in the courtyards either attached to or detached from the main house unit. Besides, in some cases where the kitchen is built separately from the main house unit it can be evaluated as auxiliary room.

- Toilet: It is a simple structure which is located away from the main house unit. 
- Bath (in some cases): They are only found in Turkish households on the island and have a distinctive dome structure [5, p. 120].

\section{Conclusion}

The vernacular houses and settlements in Cyprus exhibit harmony with the nature and the culture as a result of the appropriateness in the environmental characteristics and cultural attributes. There are several approaches and precautions in order to provide comfortable climatic conditions for the households. Houses are positioned and settled in relation with the topographic features of the related site as well. Locally available materials are used for constructing these houses. Moreover, when space usages are considered it is easily seen that they are developed in relation with the basic needs and requirements of the users.

Open space courtyards, semi-open space halls, orientation of the houses, cross ventilation, building material, hearth and roof might be listed as the main issues affecting human comfort in these spaces.

The settlements are developed either on a topography (upland or lowland) or on a slope of mountain skirts. The houses are adapted and developed in conjunction with the characteristics of the land.

Since earth, stone, timber, gypsum, local marble, reed and straw are the locally available materials in nature, they are used in the construction of these houses. Therefore, these houses might be perceived as the part of the existing texture of the nature.

Houses are arranged and formed according to the needs and the way of life of locals without bearing today's aesthetic concerns. Functionality is one of the main issues in these houses.

Unfortunately, these listed ideas, which can be described as sustainability indicators of vernacular settlements in the island, cannot be used to explain the recently developed houses and settlements on the Island. Mainly, they do not give any concern to relate themselves to the existing nature and culture. These types of houses can be seen in any other countries, which give the idea that they are selected from these foreign places and directly imported to Cyprus.

The reflection of the climatic characteristics ends up with an increase in the usage of mechanical (heating/cooling) systems as necessities to achieve climatic comfort in houses.

Since these recent houses have no relation with the environment, they do not have any consideration with the site. Instead of fitting to the site it is preferred to destroy the existing texture and make it proper to "the modern house". Besides, local materials are used only for decorative purposes in these houses.

The change in the way of life and needs cannot be neglected. In this respect, the vernacular houses cannot fit to these changing circumstances. The meaningless repetitions of existing forms and unfamiliar and unnecessary additions of foreign patterns are the common characteristics of the recently developed houses on the Island. In summary, it is obvious in this sense that there 
is too much to learn from the vernacular environments in order to achieve sustainable developments in relation with the nature and culture of the countries and societies.

\section{References}

[1] Hill Sir G., A History of Cyprus, vol. I, II, III, IV, Cambridge: Cambridge University Press, 1949.

[2] Oliver, P., (eds.), Introduction. Encyclopaedia of Vernacular Architecture of the World, vol. 1, Cambridge: Cambridge Univ. Press, pp. xxii-xxiii, 1997.

[3] Brunskill, R.W., Traditional Buildings of Britain: An Introduction to Vernacular Architecture, London: Victor Gollancz, pg.24, 1992.

[4] Oktay, M., Learning from Karpas Vernacular: Conceptualization of the Karpas Vernacular Architecture, (Unpublished Master Thesis), Dep. of Arch., Eastern Mediterranean University, Famagusta, North Cyprus, 2006.

[5] Dincyurek, O., The Rural Vernacular Architecture of Cyprus (Northern), Unpublished PhD's thesis, Eastern Mediterranean University, Famagusta, 2002.

[6] Numan, I., Dincyurek, O., Pulhan, H. "Multi Cultural Influences on the Development of Traditional Urban Fabric of Nicosia." In Proceedings of Traditional Environments in a New Millennium, defining principles and professional practice, 2nd Inter. Symposium of IAPS-CSBE Amasya, 2001.

[7] Dincyurek, O., The Adobe Houses of Mesaoria Region in Cyprus, Vol. 12., (Unpublished Master Thesis), Dept. of Arch., Eastern Mediterranean University, Famagusta, North Cyprus, 1998.

[8] Pulhan, H., Influences of the Cultural Factors on Spatial Organization of the Traditional Turkish House of Nicosia, (Unpublished Master Thesis), Dept. of Arch., Eastern Mediterranean University, Famagusta, North Cyprus, 1997.

[9] Dinçyürek, Ö., Mallick, F.H. \& Numan, I., Cultural and Environmental Values in the Arcaded Mesaorian Houses of Cyprus. Building and Environment, 38, pp. 1463-1473, 2003.

[10] Aran, K., Beyond Shelter: Anatolian Indigenous Buildings, Turkey: Tepe Architectural Culture Center, 2000. 